\title{
Formação e Ensino: Processo de hibridação intercultural na escrita sobre o ensino de língua
}

Teacher Education and Teaching: Intercultural hybridization process in writing about

language teaching

\author{
Herodoto Ezequiel Fonseca da SILVA* \\ Instituto Federal de Educação, Ciência e Tecnologia do Pará (IFPA)
}

RESUMO: Este artigo objetiva discutir os modos como as culturas escolar e local se constituem na escrita sobre o ensino de língua portuguesa de graduandos de Letras do PARFOR/UFPA, no Marajó. A base teórica está fundamentada na noção de cultura para Apple (1989; 1995) e Canclini (2013); na noção de escrita de Gnerre (1991) e Geraldi (1997); e nas de ensino de leitura e produção escrita a partir de Geraldi (2006) e Britto (1997). De um extenso corpus de escritos de graduandos, seleciona-se e analisa-se uma atividade de ensino e um diário de campo de estágio. Os escritos dos graduandos fazem referência, em sua maioria, a lendas da região inscritas na cultura vivida e na cultura como mercadoria a partir do filtro das mídias televisivas e/ou digitais e do mercado musical. Constata-se, também, o processo de hibridação das culturas marcada por indícios ora de integração, ora de contradição.

PALAVRAS-CHAVE: Formação de professores. Cultura. Escrita. Ensino de língua.

ABSTRACT: This article aims to discuss the ways in which the school and local cultures make up the writing about the Portuguese language teaching of Portuguese undergraduate students of PARFOR / UFPA, in Marajó. The theoretical basis relies on the notion of culture for Apple (1989, 1995) and Canclini (2013); in the notion of writing for Gnerre (1991) and Geraldi (1997); and in the teaching of reading and written production from Geraldi (2006) and Britto (1997). From an extensive corpus of writings made by the undergraduates, a teaching activity and a field internship diary are selected and analyzed. The writings of the undergraduates refer, in their

\footnotetext{
* Mestre e doutorando em Letras (Estudos Linguísticos) pela Universidade Federal do Pará (UFPA). Professor de Língua Portuguesa do Curso de Letras e dos Cursos Técnicos do Instituto Federal de Educação, Ciência e Tecnologia do Pará (IFPA-Campus Belém). E-mail: heroezq@yahoo.com.br.
} 
majority, to the legends of the region present in the lived culture and the culture used like merchandise from the filter of the televising and / or digital media and in the musical market. It is also observed that the process of hybridization of cultures is marked by evidence of integration as well as contradiction.

KEYWORDS: Teacher Education. Culture. Writing. Language Teaching.

\section{Introdução}

Este estudo ${ }^{1}$ objetiva discutir os modos como as culturas escolar e local (marajoara) se constituem em uma atividade de ensino de Língua Portuguesa e em um diário de campo de estágio produzidos por alunas-professoras do PARFOR/Letras da UFPA, no Marajó. Trata-se de uma reflexão que de certa forma toca na questão levantada por Geraldi (2006, p. 44): “[...] é preciso romper com o bloqueio de acesso ao poder, e a linguagem é um de seus caminhos. Se ela serve para bloquear - e disso ninguém duvida , também serve para romper o bloqueio". Sim, a linguagem é um dos caminhos para se romper com o bloqueio de acesso ao poder, que entendemos como a oportunidade de um sujeito ocupar um lugar de enunciação, dando voz a ele, à sua cultura, dialogando com as culturas outras, e ser ouvido. Entendemos que isso acontece no processo de formação de professores quando - dentre outras situações - eles refletem e escrevem sobre sua prática de ensino.

Desde 2010, tivemos a oportunidade de atuar como professor-formador no curso de licenciatura em Letras no âmbito do Plano Nacional de Formação de Professores da Educação Básica (PARFOR), experiência esta que se mostrou um campo sui generis para investigar a formação do professor de Língua Portuguesa (LP), uma vez que os graduandos atendidos por este Programa já são professores, mas sem formação de nível superior ou atuando em disciplinas diferentes daquela na qual possuem diplomação (BRASIL, 2009). A necessidade de atendimento a este público surgiu pela determinação

\footnotetext{
${ }^{1}$ Trata-se da versão escrita da comunicação oral apresentada em seção coordenada no VII Congresso Latino-Americano de Formação de Professores de Línguas, que foi realizado na Universidade Federal do Pará (UFPA), em 2018.
} 
da legislação educacional vigente (BRASIL, 1996), por meio da qual todos os professores da educação básica são exigidos a ter formação em nível superior.

Diante desse contexto, ficamos motivados em investigar os modos como os alunos-professores atendidos pelo PARFOR, na ilha do Marajó, articulam os elementos que caracterizam as culturas local e escolar em seus escritos sobre o ensino de LP. Tratase de graduandos que vivenciam a cultura escolar (enquanto professores da Educação Básica) e, em várias situações, procuram mobilizar aspectos da cultura marajoara. Eis, então, a questão que enunciamos: Como os alunos-professores do PARFOR/Letras, no Marajó, articulam as culturas escolar e local na escrita sobre o ensino de língua? A fim de responder a esta questão, analisamos enunciados selecionados de uma atividade de ensino e de um diário de campo de estágio produzidos nas disciplinas Práticas e Métodos de Ensino e Estágio Supervisionado IV, respectivamente.

Pela natureza dos dados e pela questão a ser respondida, precisamos fundamentar teoricamente o estudo nas noções de "cultura" e "hibridação cultural", principalmente pela voz de Canclini (2013), em diálogo com Apple (1989; 1995) para conseguir identificar os elementos culturais articulados nos dados. Foi necessário tratar sobre a escrita e seu estatuto para o processo de formação docente e no ensino de língua; logo, amparamo-nos em Gnerre (1991), Geraldi (1997; 2006) e Britto (1997). Essa escolha teórica foi feita a fim de conseguirmos compreender a discursivização dos referidos objetos na materialidade linguística dos textos escritos.

Este artigo apresenta, primeiramente, uma breve discussão teórica acerca das noções que fundamentam a análise dos dados para a elucidação da problemática proposta. Em seguida, analisa os enunciados e discute os resultados obtidos. A última seção destina-se às considerações finais do estudo.

\section{Cultura, Escrita e Ensino}

\subsection{No entre lugar das culturas}

Canclini (2013) demonstra uma compreensão interessante em relação ao fenômeno da hibridação cultural. $\mathrm{O}$ autor argentino preocupa-se em investigar as 
estratégias que os sujeitos mais identificados à cultura tradicional ou popular, na América Latina dos anos 90, utilizam para entrar na modernidade e sair dela. O autor lança a hipótese de que "a incerteza em relação ao sentido e ao valor da modernidade deriva não apenas do que separa nações, etnias e classes, mas também dos cruzamentos socioculturais em que o tradicional e o moderno se misturam" (CANCLINI, 2013, p. 18). Com o foco na compreensão dessa mistura, ele foge das oposições clássicas, como por exemplo, urbano e rural, moderno e tradicional, alto e popular etc.

Esta compreensão mostra-se produtiva para este estudo na medida em que tomamos o objeto "formação de professores e ensino de LP" e buscamos entender como se misturam, como se entrecruzam o "tradicional" e o "moderno" nas produções discursivas dos graduandos. Considerando o que Canclini (2013) apresenta, inferimos que o "tradicional" seria do campo do vivido, do já conhecido, do já cotidianamente produzido pelos sujeitos; e o "moderno" seria do campo da novidade, do "desconhecido", do supostamente mais atual e eficiente.

Eis a definição inicial de hibridação proposta pelo autor para demarcar sua perspectiva:

[...] entendo por hibridação processos socioculturais nos quais estruturas ou práticas discretas, que existiam de forma separada, se combinam para gerar novas estruturas, objetos e práticas. Cabe esclarecer que as estruturas chamadas discretas foram resultado de hibridações, razão pela qual não podem ser consideradas fontes puras. (CANCLINI, 2013, p. XIX) (grifos do autor).

Nota-se a noção de hibridação como processos, não algo estanque, que envolvem práticas socialmente e culturalmente situadas combinadas pelos sujeitos, resultando na produção de "novas estruturas, objetos e práticas". Essa definição possibilita-nos propor a abstração para o nosso estudo, já que seguimos este raciocínio: a formação do professor de LP no contexto do PARFOR pode ser investigada por meio do modo como se configura a escrita desses professores sobre as práticas de ensino de LP. Nossa hipótese é que essa escrita é concebida no tripé cultura escolar, cultura local cultura acadêmica ${ }^{2}$ e

\footnotetext{
${ }^{2}$ Os elementos da cultura acadêmica não são problematizados neste texto pelo fato de os dados selecionados demonstrarem agenciamento dos sujeitos mais de elementos das culturas local e
} 
que o processo de análise dos dados deve passar pelo exame dessa articulação de culturas. Basicamente, faz-nos lembrar do princípio da "autoria” para Foucault (2006, p. 28): “O autor é aquele que dá à inquietante linguagem da ficção suas unidades, seus nós de coerência, sua inserção no real".

$\mathrm{O}$ autor argentino assume que tem preferido os casos prósperos e inovadores de hibridação, isto é, aqueles em que "pode sugerir fácil integração e fusão de culturas sem dar suficiente peso às contradições e ao que não se deixa hibridar”. Entretanto, ele afirma que "hoje se tornou mais evidente o sentido contraditório das misturas interculturais", ou seja, quando a mistura dos elementos dos sistemas culturais "geram conflitos devido aos quais permanece incompatível ou inconciliável nas práticas reunidas" (CANCLINI, 2013, p. XXV).

A respeito desses casos de hibridação, tal como o professor argentino mostra, o processo de mescla pode se dar de forma mais integrativa ou mais contraditória dos elementos combinados, o que nos leva a propor a seguinte indagação: como se dá essa hibridação das culturas escolar e da tradição local nos textos dos alunos-professores?

Michael Apple, estudioso da relação entre educação e sociedade, também contribui para a compreensão da cultura. Para Apple (1989), as palavras-chave para se compreender a relação Educação e Sociedade são luta e conformação. O autor mostra seu modo de ver os fenômenos num viés estrutural, uma vez que, segundo ele, os problemas das crises são de ordem sistêmica e relacional, visto que cada problema produz outro e ambos se influenciam. Questões sociais, econômicas e culturais se afetam mutuamente.

Apple foca bastante sua atenção no papel do Estado e sua relação com a força do capital que se importa com o lucro e isso acarreta que trabalhadores tenham pouco controle formal sobre seu trabalho. Esse processo de centralização do controle do trabalho é possível ser percebido também por meio da atuação docente nas escolas. Isso se aproxima bastante do que estamos tratando: o modo como a ação didática de professores do Marajó acontece a partir de sua escrita sobre o ensino de LP, sabendo que eles - como sujeitos históricos - são afetados por forças das mais diversas, tais como, a

escolar. A problematização e a análise da cultura acadêmica constam em nossa tese que se encontra em fase de conclusão. 
sua identidade cultural marajoara, as exigências do ambiente escolar, que por sua vez são constituídas por exigências do MEC e das Secretarias de Educação. Além disso, segundo o autor, "as formas culturais ocupam precisamente aqueles mesmos espaços e potencialidades humanas que são disputados pelo capital para continuar a valorização e a acumulação capitalistas" (APPLE, 1989, p. 101).

Apple (1995, p. 82) apresenta a noção de "cultura" de duas maneiras diferentes, a saber, cultura como experiência vivida e cultura como mercadoria. O primeiro caso seria quando a cultura é concebida como "um processo social constitutivo através do qual e por meio do qual vivemos nossas vidas cotidianas" e o segundo quando é concebida como "os produtos da cultura, a própria condição de coisa das mercadorias que produzimos e consumimos".

Tais noções possibilitam a compreensão das formas como, verbi gratia, a cultura local aparece nos textos escritos pelos alunos-professores. Um exemplo seria quando, em seu diário de campo, um aluno-professor relata uma aula por ele ministrada, que tinha como objetivo trabalhar narrativas regionais de cunho folclórico. No entanto, o graduando utiliza quadrinhos da turma da Mônica como recursos didáticos para subsidiar o contato dos alunos com textos dessa natureza e para subsidiar atividades de compreensão e interpretação de texto. Em uma situação desse tipo, fica claro que se trata de um objeto cultural (os quadrinhos da turma da Mônica), mas concebido por um mercado editorial que apresenta apenas um "simulacro" do folclore brasileiro. Trata-se, portanto, de uma expressão da cultura pela perspectiva do mercado.

\subsection{A escrita na formação docente e no ensino de língua}

Para este trabalho, compreendemos que a escrita reflete as relações sóciohistóricas vividas pelos sujeitos, tal como Gnerre (1991) e Geraldi (1997) ensinam. A escrita analisada neste artigo é de professoras do Marajó, no contexto de um curso superior de licenciatura, que requer - ou pelo menos deveria requerer - atenção às exigências normativas, teóricas e metodológicas de um trabalho escrito na universidade. Como consequência, teremos uma escrita que refletirá, em seu conteúdo e em seu estilo, 
as relações dessas "forças", seja baseada na produção de enunciados novos, ou mesmo na reprodução de enunciados.

De acordo com Britto (1997, p. 84), a escrita "surge como uma forma definitiva de registro em razão de desenvolvimento do comércio e da propriedade privada, bem como da sofisticação de procedimentos litúrgicos". Assim também, hoje, a escrita ocupa lugar de destaque nos cursos superiores de formação de professores, pois é por meio dela que o conhecimento sobre o ensino passa a ser produzido, difundido, polemizado, enfim, ampliado. De maneira mais específica, a escrita desempenha um importante papel no processo de formação docente, quando os licenciandos são solicitados a produzir diários de campo, relatórios, relatos autobiográficos, narrativas etc. durante disciplinas voltadas às metodologias de ensino de língua (Ensino-aprendizagem, Prática de Ensino, Estágio Supervisionado, entre outros títulos), momentos em que os licenciandos devem ir ao ambiente escolar e registrar sua experiência de observação e de regência de aulas de LP. Lembremos ainda do papel da escrita para a integralização total do curso que passa pela produção de um trabalho monográfico de final de curso.

A respeito do que Britto (1997) propõe sobre os três períodos na história da produção de gramáticas na tradição ocidental, focamos nossa atenção no que o autor expõe sobre o terceiro período:

O terceiro período [...] relaciona-se com os novos processos de produção e de relação social que se instituem com a revolução industrial e as sociedades de massas, a partir do final do século XVIII, e se caracteriza pela vulgarização da escrita, que de uma técnica restrita a pequenos grupos passa a ser uma necessidade do próprio processo de produção e consumo [...]. (BRITTO, 1997, p. 89).

Pode-se fazer a aproximação entre este dado histórico apresentado por Britto com a problemática aqui discutida que perpassa a questão da escrita na universidade, pois para que o processo de produção e de consumo do conhecimento científico aconteça são necessários o domínio e o uso da escrita. Deslocando essa discussão para a escrita do professor na escola - deslocamento esse que acreditamos ser menos frequente nas pesquisas comparado com a escrita na academia - percebemos que também é bastante necessário utilizar a escrita para a efetivação do trabalho docente, em suas atividades didáticas, administrativas (de cunho mais burocrático) e de pesquisa. 
Com relação a esse aspecto, Britto (1997,) destaca o movimento paradoxal de inclusão e exclusão dos indivíduos ao universo da escrita:

[...] a escrita surge como uma tecnologia cujo domínio do ponto de vista social, é necessário para o desenvolvimento da economia, e, do ponto de vista do indivíduo, como condição de inserção social. Constituiu-se, então, um espaço de produção social em que à escrita se vincula, muito mais que uma possibilidade de expressão de cultura ou forma de pensamento, uma necessidade pragmática [...]. (BRITTO, 1997, p. 91) (negritos meus; itálicos do autor).

Tem-se o domínio da escrita como condição de inserção social e, no âmbito da universidade, condição de inserção acadêmica e, posteriormente, inserção no grupo dos letrados da sociedade. É o movimento pelo qual os alunos-professores do PARFOR Letras - contraditoriamente, pois já são professores e pressupõem-se letrados - são chamados a se inserir nos espaços de produção do conhecimento científico, visando à “qualificação", tal como concebe o documento normativo do PARFOR (BRASIL, 2009).

No que diz respeito ao ensino da escrita, Geraldi (2006, p. 40) afirma que

[...] toda e qualquer metodologia de ensino articula uma opção política - que envolve uma teoria de compreensão e interpretação da realidade - com os mecanismos utilizados em sala de aula. [...] Assim, os conteúdos ensinados, o enfoque que se dá a eles, as estratégias de trabalho com os alunos, a bibliografia utilizada, o sistema de avaliação, o relacionamento com os alunos, tudo corresponderá, nas nossas atividades concretas de sala de aula, ao caminho por que optamos.

É justamente a essa "opção política” que nos atentamos neste artigo: nos modos como os alunos-professores articularam suas opções (de textos, de tipos de questões, de tipos de abordagem, de conteúdos) em seus escritos.

Outra questão relevante sobre o ensino de língua levantada por Geraldi, na década de 1980 - mas ainda atual - diz respeito ao ensino da metalinguagem, que segundo ele, "mais modernamente, as descrições tradicionais foram substituídas por descrições da teoria da comunicação, e hoje o aluno sabe o que é emissor, receptor, mensagem, etc. $\mathrm{Na}$ verdade, substituiu-se uma metalinguagem por outra!"' (GERALDI, 2006, p. 46).

Acrescentamos que hoje - com a promulgação da Base Nacional Comum Curricular (BNCC), mas na verdade, desde o final da década de 90, com a publicação dos 
Parâmetros Curriculares Nacionais (PCNs) de Língua Portuguesa - a metalinguagem adotada é a dos gêneros textuais / discursivos, perpassando pelo modo como a interação se organiza nos textos didáticos produzidos pelos professores e nos diálogos em sala de aula. Nota-se que a escolha dos gêneros textuais / discursivos como objeto de ensino parece mostrar-se amparada em uma pretensa concepção interacionista (ou "enunciativodiscursiva"), antagonizando-se às descrições e nomenclaturas gramaticais, mesmo em vários momentos este trabalho gramatical se fazer presente no discurso pedagógico que materializa a cultura escolar. A esse respeito, concordamos com Possenti (2006, p. 38) quando afirma que "o domínio efetivo e ativo de uma língua dispensa o domínio de uma metalinguagem técnica".

\section{Hibridação intercultural na escrita de professores}

Como já foi explicado anteriormente, a atividade de ensino aqui analisada foi produzida em uma disciplina de Práticas e Métodos de Ensino ${ }^{3}$ do curso de Letras. Essa atividade foi elaborada a partir das seguintes condições: solicitamos a produção e a socialização de material didático que contemplasse elementos da cultura local, ou seja, a cultura marajoara (histórias, narrativas, literatura, músicas, aspectos históricos, aspectos geográficos, entre outros). Além disso, era preciso que o material considerasse as orientações teórico-metodológicas que foram estudadas na disciplina e que contivesse atividades de compreensão/interpretação de texto, atividades de reflexão/análise de aspectos da língua e atividades de produção de texto.

O diário de campo selecionado para análise foi produzido na disciplina Estágio Supervisionado $I V^{A}$. Esse diário foi elaborado a partir das seguintes condições: após a aluna-professora ter produzido um plano de ensino de LP para ser aplicado na escola em que atuava, ela deveria, durante a aplicação, registrar por escrito o dia a dia no ambiente escolar, a fim de coletar dados sobre a caracterização da escola, dos alunos e os eventos

\footnotetext{
${ }^{3}$ Trata-se da disciplina intitulada "Oficina de Práticas e Métodos de Alfabetização, Letramento e Letramento Digital”, que é ofertada no $7^{\circ}$ período do curso.

${ }^{4} \mathrm{O}$ "Estágio Supervisionado IV" é ofertado no $8^{\circ}$ período do curso.
} 
ocorridos durante a regência das aulas. Sua prática de ensino ocorreu em uma turma de Ensino Fundamental em escola situada na zona rural de Curralinho.

Organizamos a análise dos enunciados, considerando duas categorias elaboradas a partir do estudo de Canclini (2013) já mencionado na seção 1.1. O autor afirma haver casos prósperos e inovadores de hibridação das culturas e, por outro lado, casos em que se sobressai o sentido contraditório das misturas interculturais. Analisaremos o processo de hibridação entre os elementos das culturas escolar e local nos textos das graduandas a partir dessa perspectiva. Por conta disso, elaboramos as categorias de hibridação integrativa e hibridação contraditória. Estamos cientes de que fazer uma análise aprofundada sobre esse problema de pesquisa necessitaria de um arquivo maior de enunciados (FOUCAULT, 2016), o que não é possível em um artigo científico (devido a sua natureza e extensão) ${ }^{5}$. Por esse motivo é que fazemos a discussão sobre esse problema a partir de alguns indícios encontrados nos enunciados selecionados.

\subsection{Indícios de hibridação integrativa}

O excerto a seguir é um trecho de uma atividade de ensino produzida por graduandas da referida turma que tinha como dois de seus objetivos "desenvolver a capacidade de leitura do aluno" e "aperfeiçoar a habilidade de compreensão e interpretação de lendas regionais", e elegia como objeto de ensino o "gênero textual lendas". As graduandas propuseram, primeiramente, a realização de uma roda de conversa a partir de uma primeira leitura da "lenda do açaí" para depois entregar as questões de compreensão / interpretação do texto. O texto sobre a lenda do açaí escolhido foi a versão de um escritor que reside na cidade de São Sebastião da Boa Vista: Silvestre de Oliveira Costa. Logo após o texto intitulado "A lenda do açaí'” (COSTA, 2015), as graduandas apresentavam nove questões, dentre as quais questões de compreensão e de interpretação textuais e questões de metalinguagem e de análise linguística envolvendo classes de palavras. A seguir, transcrevemos apenas as questões de número 1, 2, 3, 5 e 9.

\footnotetext{
${ }^{5}$ Frisamos que as análises mais ampliadas desse corpus e de outros textos encontram-se em nosso texto de tese que se encontra em elaboração.
} 
(1)

1- Quais personagens aparecem na lenda? A que comunidade pertencem?

2- Que informações geográficas o primeiro parágrafo da lenda nos traz?

3- A lenda narra que o cacique tomou uma decisão muito cruel, qual foi? Que

razões o levaram a essa decisão?

$[\ldots]$

5- Segundo a lenda, como é o nome da árvore de onde nasce o açaí? Era por

este nome que você conhecia? Se sua resposta for não, escreva os outros nomes pelos quais esta árvore é conhecida?

[...]

9- Sublinhe os adjetivos no texto abaixo.

"O açaí é natural, completo e puro, sem aditivos e não contém agrotóxicos. É

Rico em Proteínas, Lipídios Insaturados, Vitamina E, A e Complexo B, Fibras, Potássio, Cálcio, Fósforo, Magnésio, Zinco, Ferro e outros Minerais. Muitas pessoas ingerem este alimento sem saber que, além de ser delicioso e dar muita energia, é também muito benéfico à saúde [...]."

Fonte: http://gastronomiahoje.blogspot.com/2012/08/acai-caracteristicas-da-fruta.html.

O primeiro ponto a se destacar é a escolha de uma "lenda" (a lenda do açaí) para atender à solicitação do professor-formador de abordarem aspectos da cultura local nas atividades produzidas. É interessante notar que existem várias versões dessa lenda que circulam em livros diversos, sítios eletrônicos e vídeos na internet, no entanto a versão escolhida para exercer a função de material linguístico-discursivo de base para a questão foi a de um autor local, demonstrando a mobilização de elemento da cultura local a partir da prática cotidiana das graduandas (como experiência vivida).

No que diz respeito às questões, a primeira, a segunda e a terceira são de identificação de informações explícitas no texto acerca das personagens, suas ações e o espaço da narrativa. A terceira questão chama atenção, pois nela as graduandas parafraseiam uma parte do conteúdo do texto por meio de uma estrutura de discurso indireto (A lenda narra que...), dando voz ao texto e estabelecendo a mediação pedagógica entre o texto-base da questão e a resposta do aluno. Trata-se de um trabalho enunciativo por meio do qual as alunas-professoras trazem um elemento da cultura local (a lenda) para um discurso pedagógico que constitui uma atividade de ensino da leitura próprio da cultura escolar.

A quinta questão é composta por três perguntas: a primeira é de identificação de informação explícita acerca do nome da árvore onde nasce o açaí; as outras duas perguntas são de extrapolação do conteúdo do texto a fim de dialogar com os saberes dos alunos da escola acerca de por quais nomes os alunos conhecem a palmeira do açaí. Entendemos que seja um procedimento de ensino da leitura baseado na interlocução com 
os alunos que visa ao diálogo com os elementos da cultura local pelo ponto de vista dos alunos, de suas práticas cotidianas. Além disso, a última pergunta pode ser útil para ampliar o repertório lexical dos alunos em relação aos diferentes modos de nomear a palmeira onde dá o açaí, pois, segundo o sítio eletrônico da Agência Embrapa de Informação Tecnológica (2019), pode ser chamada de "açaizeiro", "açaí-de-touceira", "jussara" e "jussara-de-touceira"

$\mathrm{Na}$ continuação desse mesmo material didático, na nona questão, solicitam que adjetivos sejam sublinhados de um texto informativo, de oito linhas, retirado de um site (blog) da internet, sobre as características nutricionais e os benefícios do açaí. Percebe-se a continuidade da temática do "açaí", no entanto já trazendo um texto de um meio de circulação midiático que, dentre uma de suas funções em um blog, seria o de "vender" a imagem positiva do fruto, uma vez que agrega valor ao açaí por meio da grande quantidade de qualificadores positivos e das informações nutricionais. Ou seja, ocorre a permanência do tema de um elemento da cultura marajoara, na atividade de ensino, pela perspectiva do mercado pelo meio de circulação da mídia digital.

Essa articulação entre as culturas continua neste material. Nas próximas duas aulas planejadas, solicita-se, primeiramente, que os alunos leiam mais duas lendas contidas em Costa (2015): “a lenda do açaí e açaiara" e "a lenda do nome açaí". Em seguida, solicita-se que os alunos escutem a música "Sabor açaí", do compositor e cantor paraense Nilson Chaves, com o auxílio da letra da música impressa ${ }^{7}$. As graduandas elaboraram nove questões de compreensão e interpretação para trabalharem a didatização da música, dentre as quais transcrevemos apenas as duas primeiras e a quinta.

(2)

1- Qual a relação da música "sabor açaî" com as lendas lidas?

6 AGÊNCIA EMBRAPA DE INFORMAÇÃO TECNOLÓGICA. Açaí. Disponível em: http://www.agencia.cnptia.embrapa.br/gestor/acai/arvore/CONT000gbfan1e702wx5ok07shnq97 wntcgb.html\#. Acesso em: 14 fev. 2019.

${ }^{7}$ Lançada ainda no início da década de 1990, essa canção é uma das mais conhecidas de uma faceta da cultura amazônica, que ganhou repercussão no mercado musical nacional e internacional. É muito comum, quando falam da forte presença do açaí na cultura amazônica, fazerem alusão a esta canção. 
2- Com qual das lendas lidas a música mais se relaciona? Destaque os trechos que fizeram com que você chegasse a essa conclusão.

$[\ldots]$

5- Em sua opinião, que mensagem a música quer transmitir sobre o açaí?

Dessa forma, as graduandas, autoras desse material didático, articularam textos de natureza, esferas culturais e meios de circulação diferentes buscando o ensinoaprendizagem de aspectos da leitura: (i) lendas sobre o açaí retiradas de um livro produzido por um autor local, (ii) um texto informativo sobre as características nutricionais e os benefícios do açaí retirado da internet e (iii) a música "Sabor açaí", do compositor paraense. É interessante notar que além de eles articularem esses materiais linguísticos para constituir o discurso pedagógico do material didático, eles também conduzem o processo de aprendizagem dos alunos de compreensão dos textos também baseado na articulação, na relação entre os textos, ou ainda na relação interlocutiva (GERALDI, 1997) entre os textos e entre os alunos e os textos, tal como se percebe nas duas consignas acima do exemplo (2).

Esses dados dão indícios de um processo de hibridação intercultural, uma vez que elementos das culturas marajoara e escolar se misturam na construção de um produto cultural singular, ora com marcas sócio-históricas de - pela ótica de Apple (1989; 1995) - práticas cotidianas vividas e de práticas passadas pelo filtro do mercado das mídias digitais e da música nacional. Afirmamos se tratar de uma "música nacional" porque, assumindo as contribuições de Canclini (2013), "Sabor açaî" é, a nosso ver, um típico exemplo de um produto cultural cuja concepção se deu no campo do tradicional, mas logo ganhou status de moderno, ou seja, situa-se em um entre lugar onde o tradicional e o moderno se misturam.

A articulação dos elementos culturais nos textos e nas questões que compõem o material didático conduz, a partir da leitura que fizemos, à integração produtiva, construindo os nós de coerência (FOUCAULT, 2006) no material para os sujeitos envolvidos, em suas condições históricas e culturais.

Processos discursivos diferenciados são analisados na próxima seção.

\subsection{Indícios de hibridação contraditória}


Observemos o seguinte excerto agora de um diário de campo produzido para registrar a implementação da proposta didática de uma aluna-professora em uma escola da zona rural de Curralinho.

(3)

Em seguida perguntei para eles o que entendiam ou se já tinham estudado o que é lendas. A sala ficou em total silencio, esperei eles pronunciarem-se apenas dois falaram que lenda era antigo coisa sobrenaturais. Expliquei que lendas são narrativas transmitidas oralmente pelas pessoas, nelas acontecem casos misteriosos ou sobrenaturais, há uma mistura de fatos reais com fantasias e que elas vão sendo contadas e modificadas através da imaginação do povo. Informei que as nossas aulas iremos estudar sobre as lendas locais do rio mutuacá. Mencionei várias lendas como a do saci, da iara, mula sem cabeça, do boto. Realizei a lenda do saci, logo em seguida escrevi a mesma no quadro pedir para os discentes lerem durante a realização da leitura a presentaram dificuldades, sendo que não respeitam os sinais de pontuações. Pedir para observarem com atenção quando eu estiver lendo, convidei eles para lermos juntos, depois expliquei que durante a leitura é importante respeitar as pontuações e que cada ponto e virgulas tem uma importância e seu valor para poder o ouvinte e quem ler entender o que está sendo lido.

O primeiro ponto a destacar é que a aluna-professora valorizou um tipo de saber da cultura local. Por exemplo, o fato de ela eleger como objeto de ensino "lendas" possivelmente do conhecimento dos alunos: saci, iara, boto etc. No entanto, chama-nos atenção o modo como esse saber tradicional é transposto para a cultura escolar: o saber sobre as lendas é levantado a partir de conhecimentos metalinguístico dos alunos sobre as mesmas uma vez que pergunta "se já tinham estudado o que é lendas". Ou seja, se conheciam o referido conjunto de textos por meio de estudo sistematizado e formal escolar, e ainda com o uso da fórmula interrogativa "o que é" solicita-se se os alunos dominam a definição ou conceituação de tais textos.

Em seguida, ela afirma que as "lendas são narrativas transmitidas oralmente pelas pessoas", mas, na sequência do fragmento, ela narra a leitura que fez de uma lenda ao invés de contar uma que soubesse (se assim o fizesse, instauraria um saber local). Ao invés de, pelo menos nesse primeiro momento, contar oralmente a lenda do saci e pedir que os alunos contassem livremente lendas que conhecessem, ela leu, escreveu no quadro e fez os alunos também lerem em voz alta (práticas reconhecidamente bem tradicionais da cultura escolar). 
Além disso, a professora foca sua atenção diretamente nos sinais de pontuação que constituem um dos aspectos da convenção dos textos escritos próprios da norma padrão culta da língua. Consideramos que o surgimento desses elementos no relato da aula representa uma forma como a cultura escolar se faz presente no discurso, na forma de um relato que é também a afirmação da validade desse conteúdo de ensino em uma cultura escolar em que se desenvolve a aula de LP fortemente marcada pelos aspectos próprios da modalidade escrita da língua. Mesmo elegendo um texto que supostamente fosse próximo aos alunos, ou seja, um texto com o qual os alunos têm contato cotidianamente, a escrita do relato demonstra um ensino que explora não esses aspectos cotidianos de contação das lendas, mas aspectos formais de acordo com as convenções da escrita.

Voltando ao início do excerto, ela narra que perguntou aos alunos o que eles entendiam e o que já tinha estudado sobre as lendas. Inferimos que os alunos não conseguiram entender o que lhes fora perguntado ("A sala ficou em total silêncio"), já que a pergunta da professora pedia uma resposta de metalinguagem sobre o "gênero lenda". Ou então podem ter entendido a pergunta e saberem, do seu jeito e segundo suas experiências, o que são lendas, mas pelo fato de ter sido a professora que fez tal questionamento, poderiam supor que o que ela solicitava como resposta não correspondia ao que eles sabiam sobre tais textos.

Trata-se de um "problema" no processo de responsividade dialógica em sala de aula, pois os alunos não demonstraram identificação aos sentidos daquele questionamento, dificultando sua inserção na interação verbal. Continuando essa linha de análise, em apenas dois falaram que lenda era antigo coisa sobrenaturais, traz a voz dos alunos em discurso indireto, introduzido pelo modalizador apreciativo "apenas", demonstrando o ponto de vista do locutor de que foram poucos que participaram e subentende-se que esperava que mais alunos participassem. Causa estranheza a forma como a professora estruturou a resposta de dois alunos, a saber, "lenda era antigo coisa sobrenaturais": em uma primeira leitura podemos lembrar daqueles exemplos de frases agramaticais em manuais de linguística, no entanto, lendo com mais atenção e percebendo essa frase na progressão do texto, poderíamos reescrevê-la pensando em como os alunos poderiam ter respondido: a lenda é uma história antiga e com coisas 
sobrenaturais. A forma como a professora escreveu pode ter materializado a falta de atenção à voz dos alunos ou mesmo a dificuldade que os alunos tiveram em responder, por se tratar de uma demanda de metalinguagem.

Por outro lado, também observamos o fato de que há uma série de problemas na escrita da aluna-professora que violam os princípios que ela afirma ter em relação aos sinais de pontuação. Por exemplo, embora ela afirme que os alunos têm que saber respeitar a pontuação, mencionando os pontos e as vírgulas, podemos localizar, em seu próprio texto, diversos desvios de pontuação: na primeira linha, a professora não usa a vírgula após a expressão de marcação cronológica Em seguida; na segunda linha, ela não emprega um ponto seguido após o período "esperei eles pronunciarem-se"; após a oração Realizei a lenda do saci, seria mais adequado utilizar um ponto seguido ao invés da vírgula; entre outros. Há também desvio de concordância verbal em o que é lendas, erros de ortografia quando escreve o verbo "pedir" no pretérito perfeito para narrar suas ações em sala, ela escreve o verbo em forma de infinitivo: pedir para os discentes lerem e Pedir para observarem com atenção quando eu estiver lendo ${ }^{8}$.

Dessa forma, pode-se notar que a presença do discurso escolar "tradicional" instaura uma contradição na posição da aluna-professora entre o que é dito e o como é dito, a maneira como estão mobilizados os recursos linguísticos. De um lado temos o plano do "conteúdo temático" de um ensino por meio de lendas supostamente locais e a atenção ao aspecto do cuidado com a pontuação no momento da leitura em voz alta das lendas. De outro, temos o plano do "estilo" por meio do qual se demonstra o próprio ato de afirmar esse conteúdo, a partir de um ensino de língua baseado na nomenclatura gramatical com uma escrita recheada de problemas de pontuação, de ortografia. Trata-se de um sujeito que mostra sua exclusão do modelo de educação que defende por conta dessa relação conflitante em seu texto. Utilizando outras palavras, ela, por já ser professora, enuncia de um lugar de poder da cultura escolar, mas uma cultura escolar do lugar de contradição, porque com a força instituída historicamente do discurso escolar

\footnotetext{
${ }^{8}$ A menção a esses pontos um pouco mais normativos no escrito da aluna-professora serve para o nosso intento de análise, ou seja, funcionam como indícios das relações de poder entre o discurso pedagógico e o discurso da cultura marajoara inscritos no texto da graduanda. Tais pontos não foram o foco principal durante a ação formativa, pois a escrita dos diários de campo objetivava principalmente a riqueza dos registros da vivência de estágio.
} 
descaracteriza e silencia as vozes que poderiam ser evocadas advindas da cultura local. Configura-se, assim, um discurso fragilizado por não apresentar toda a correção que ela mesma prescreve. Nesta zona fronteiriça entre a cultura escolar e a cultura local, a articulação delas acontece de forma conflituosa e contraditória, resultando no silenciamento da segunda.

\section{Considerações finais}

Em síntese, nosso objetivo foi de discutir os modos como as culturas escolar e local se articulam na escrita de uma atividade de ensino de LP e de um diário de campo de estágio produzidos por alunas-professoras do PARFOR/Letras da UFPA. Para tanto, buscamos embasamento teórico em noções como as de cultura, hibridação cultural, escrita e ensino de língua.

Foi possível perceber que os textos analisados refletem as relações sóciohistóricas vividas pelos sujeitos. São textos escritos (de cunho didático-pedagógico) produzidos por alunas-professoras do Marajó, no contexto de um curso superior de licenciatura no âmbito de um programa governamental; uma escrita que reflete, em seu conteúdo e em seu estilo, as relações integrativas e contraditórias dessas "forças", seja baseada na produção de enunciados novos, na reprodução de enunciados e em sua articulação.

Constatamos, na atividade de ensino, indícios do que chamamos de hibridação integrativa uma vez que as autoras do material articularam os elementos da cultura escolar e da cultura marajoara por meio da associação entre os enunciados de naturezas diferentes e advindos de meios de circulação diferentes, mas que no produto "final" notase coerência e construção da possibilidade de interlocução dos textos com os alunos por meio das consignas. Foi possível notar ainda que os elementos da cultura marajoara são mobilizados ora como experiência vivida (práticas de seu cotidiano) ora como produto de mercado (produtos culturais elaborados por outrem a partir dos elementos de sua cultura).

Já no excerto do diário de campo, observamos indícios do que nomeamos de hibridação contraditória. A aluna-professora demonstrou dificuldade em considerar os saberes da cultura local quando tenta relacionar com os saberes da cultura escolar. Isso se 
deu pela presença do discurso escolar "tradicional" instaurando uma contradição na posição da aluna-professora pelo conteúdo do dizer e pela forma do dizer, a maneira como estão mobilizados os recursos linguísticos.

Percebemos ainda, neste dado, o ensino da metalinguagem, mas hoje a expressão "ensino da metalinguagem" não se configura da mesma forma como no tempo do texto de Geraldi (década de 80). Neste dado, há um ensino da metalinguagem dos gêneros textuais / discursivos, ou o que chamamos de "ensino metagenérico". Trata-se de planos de aula, atividades de leitura, de escrita e "análise linguística" e procedimentos de ensino em sala de aula voltados para uma nomenclatura sobre os gêneros textuais / discursivos. Entendemos que isso se dá porque a aula pode ser concebida a priori, já "pensada" a partir de orientações teóricas e metodológicas que estão "na moda" ou de "preconceitos" do que vem a ser o ambiente escolar, os alunos e as aulas de LP, cabendo ao professor apenas executar a aula, tomando o sentido proposto por Apple $(1989 ; 1995)$.

\section{REFERÊNCIAS}

AGÊNCIA EMBRAPA DE INFORMAÇÃO TECNOLÓGICA. Açaí. Disponível em: http://www.agencia.cnptia.embrapa.br/gestor/acai/arvore/CONT000gbfan1e702wx5ok07 shnq97wntcgb.html\#. Acesso em: 14 fev. 2019

APPLE, M. Resistência e contradições na classe, na cultura e no Estado: a cultura como experiência vivida - II. In: APPLE, M. Educação e Poder. Tradução de Maria Cristina Monteiro. Porto Alegre: Artes Médicas, 1989.

. Cultura e comércio do livro didático. In: APPLE, M. Trabalho Docente e

Textos: economia política das relações de classe e de gênero em educação. Tradução de Thomas Tadeu da Silva, Tina Amado e Vera Maria Moreira. Porto Alegre: Artes Médicas, 1995.

BRASIL. Decreto ${ }^{\circ}$ 6.755, de 29 de janeiro de 2009. Institui a Política Nacional de Formação de Profissionais do Magistério da Educação Básica. Brasília, DF, 29 jan. 2009.

BRASIL. Lei N 9394, de 20 de dezembro de 1996. Estabelece as Diretrizes e Bases da Educação Nacional. Brasília, DF, 20 dez. 1996. 
BRITTO, L. P. L. A sombra do caos: ensino de língua x tradição gramatical. Campinas, SP: Mercado de Letras, 1997.

CANCLINI, N. G. Culturas Híbridas: estratégias para entrar e sair da modernidade. Tradução de Ana Regina Lessa e Heloísa Pezza Cintrão. Tradução da Introdução de Gênese Andrade. 4. ed. São Paulo: Editora da Universidade de São Paulo, 2013.

COSTA, S. O. O açaí e suas lendas. São Sebastião da Boa Vista, Marajó: produção do próprio autor, 2015. 
FOUCAULT, M. A Arqueologia do Saber. Trad. Luiz Felipe Baeta Neves. 8. ed. Rio de Janeiro: Forense Universitária, 2016. . A ordem do discurso. Tradução de Laura Fraga de Almeida Sampaio. 14. ed. São Paulo: Edições Loyola, 2006.

GERALDI, J. W. Concepções de linguagem e ensino de português. In: GERALDI, J. W. (org.). O texto na sala de aula. 4. ed. São Paulo: Ática, 2006, p. 39-46. . Portos de Passagem. 4. ed. São Paulo: Martins Fontes, 1997.

GNERRE, M. Linguagem, escrita e poder. São Paulo: Martins Fontes, 1991.

POSSENTI, S. Sobre o ensino de português na escola. In: GERALDI, J. W. (org.). $O$ texto na sala de aula. 4. ed. São Paulo: Ática, 2006, p. 32-38.

SOUZA, Olegario Martins de. Características do acai. Blog gastronomia hoje. Ceará, 27 ago. 2012. Disponivel em: http://gastronomiahoje.blogspot.com/2012/08/acaicaracteristicas-da-fruta.html. Acesso em: 18 set. 2019 